\title{
Farklı yağlı tohumlardan soğuk pres yöntemiyle elde edilen sabit yağların yağ asidi kompozisyonlarının araştırılması
}

Investigation of fatty acid compositions of obtained from different oilseeds by cold pressed method

\section{Hasan ASiL ${ }^{1 / \infty}$, Dilşat BOZDOĞAN KONUŞKAN ${ }^{2}$}

${ }^{1}$ Hatay Mustafa Kemal Üniversitesi, Altınözü Tarım Bilimleri MYO, Tıbbi ve Aromatik Bitkiler Programı, Antakya, Hatay.

${ }^{2}$ Hatay Mustafa Kemal Üniversitesi, Ziraat Fakültesi, Gıda Mühendisliği Bölümü, Hatay.

MAKALE BILGISI / ARTICLE INFO

Makale tarihçesi / Article history:

DOI: $10.37908 /$ mkutbd.959699

Geliş tarihi /Received:29.06.2021

Kabul tarihi/Accepted:02.09.2021

\section{Keywords:}

MUFA, PUFA, SAT, soğuk pres, yağ asidi.

$\checkmark$ Corresponding author: Hasan ASIL

$\square:$ hasanasil@mku.edu.tr

\section{ÖZET / ABSTRACT}

Aims: In this study, it is aimed to determine the fatty acid compositions of obtained from Almond, Black Cumin, Terebinth, Chia, Mustard, Bitter Apricot Kernel, Native Sesame, White Sesame, Flax, Safflower, Canola, Poppy, Peanut, and Coconut nutmeg oils by cold pressing method.

Methods and Results: A single head screw cold press (Koçmaksan, İzmir, $1.5 \mathrm{~kW}, 220$ volts) with a crushing capacity of $5 \mathrm{~kg}$ per hour was used for the extraction of oils from plants. Obtained oils were filtered with filter paper to remove particulates and filled into $10 \mathrm{ml}$ brown glass bottles without any air space and stored at $-18^{\circ} \mathrm{C}$ until analysis. When these plants were evaluated in terms of fatty acid composition, it was determined that they contain nine saturated, six monounsaturated, and seven polyunsaturated fatty acids. The highest total saturated fatty acid was obtained from coconut oil with $84.78 \%$. The highest total unsaturated fatty acid content was obtained from Canola oil with $91.19 \%$, the highest monounsaturated fatty acid content was obtained from Bitter Apricot kernel oil with $67.04 \%$, and the highest polyunsaturated fatty acid content was obtained from hashish with $69.76 \%$. The $P$ (polyunsaturated fatty acids) / $\mathrm{S}$ (saturated fatty acids) values of the plants whose oil is extracted by the cold pressing method vary between $0.02-10.43$. The highest $P / S$ values of the oils were obtained from Canola with $10.35 \%$ and bitter apricot kernel oil with $9.96 \%$, respectively.

Conclusions: Coconut oil remains below World Health Organisation (WHO) standards in terms of $\mathrm{P} / \mathrm{S}$ value and is classified as non-consumable directly as food. It has been concluded that the other cold-pressed oils examined may be among the oils that can be used as edible oils in terms of both closing the edible oil industry gap and health benefits due to having a balanced fatty acid composition.

Significance and Impact of the Study: Oils are used in many fields such as oils, edible oil, soap, perfumery, and other industries according to their fatty acid composition. In this study, the chemical data of the oils obtained by cold pressing are combined in a single data set to provide easy data for researchers.

Atıf / Citation: Asil H, Bozdoğan Konuşkan D (2021) Farklı yağlı tohumlardan soğuk pres yöntemiyle elde edilen sabit yağların yağ asidi kompozisyonlarının araştırılması. MKU. Tar. Bil. Derg. 26(3) : 670-678. DOI: 10.37908/mkutbd.959699 


\section{GíRiş}

Yağlar, beslenmede önemli yer tutan temel bileşenlerden olup, enerji vermesinin yanı sıra, esansiyel yağ asitlerini içermesi, yağda çözünen vitaminlerin vücuda alımını sağlaması gibi önemli özelliklere sahip yalnızca organik çözücülerde çözünebilen bileşiklerdir (Altan ve Kola, 2009). Günümüzde yemeklik olarak kullanılan yağlar kaynaklarına göre bitkisel ve hayvansal veya katı ve sıvı yağlar olarak gruplandırılmaktadır (Kayahan, 2003). Bitkisel yağlar ise yağlı tohum ve meyvelerden elde edilmektedir (Altan ve Kola, 2009).

Yağlı tohumlardan yağın ekstraksiyonunda genellikle presleme, çözücü destekli yağ ekstraksiyonu, süper kritik sıvı destekli ekstraksiyon yöntemi, mikrodalga destekli ve ultra ses destekli ekstraksiyon yöntemleri kullanılmaktadır (Sevindik ve Selli, 2017; Asil ve Göktürk, 2020). Bu yöntemlerden son yıllarda en yaygın kullanılanı ise, tamamen mekanik olarak ve kimyasal kullanılmadan elde edilen soğuk pres yöntemleridir (Bozdoğan Konuşkan, 2020). Türk Gıda Kodeksi Bitki Adı ile Anılan Yağlar Tebliği'ne göre soğuk preslenmiş natürel yağlar doğrudan tüketime uygun olan, ısıl işlem olmaksızın sadece mekanik yöntemle elde edilen yağlar olarak tanımlanmıştır (TGK, 2012).

Soğuk pres yöntemi, bir bitkinin meyvesi, tohumu veya çekirdeği gibi yağlı bileşenlerinin dışarı dikkatli atılması ve mekanik ısı uygulaması olmadan ve kimyasal çözücü kullanmadan preslenerek elde edilen yağın yalnızca filtrelenmesi ve şişelenmesi işlemidir (Asil, 2020). Soğuk pres yağlar ağırlıklı olarak ilaç ve kozmetik sanayinde ve sofralarda yoğun şekilde kullanılmaktadır (Gürpınar ve ark., 2011). Düşük sıcaklıkta işlenmesi sayesinde yağın fenolik içeriği, lezzet, aroma ve besin değeri gibi özellikleri değişmeden kalır (Asil, 2020). Soğuk pres tekniğinin dezavantajı ise elde edilen yağ veriminin düşük olmasıdır. Soğuk preslenmiş bitkisel materyal hala bir miktar yağ içerebildiği için çıkan küspeden çözgen ekstraksiyonuyla kalan yağın alınması sağlanabilir (Duran ve ark., 2020). Soğuk preslenmiş yağ, trans yağ asitleri içermez ve yemek pişirme ve temel cilt bakımı gereksinimleri açısından büyük önem taşır (Chandra ve ark., 2020). Yapılan çalışmalarda soğuk preslenmiş yağlarda bulunan minör biyoaktif lipidlerin, antiinflamatuar, antimikrobiyal, antikanser, antidiyabetik, antihipertansif ve düşük yoğunluklu lipoproteinin düşürülmesi gibi insan sağlığı üzerinde faydalı etkilere sahip olduğu belirtilmiştir (Ibrahim ve ark., 2017; Konuskan, 2020; Dogruer ve ark., 2021). Ayrıca bu biyoaktif bileşikler, yağın oksidatif stabilitesini artırarak raf ömrünün uzatılmasında da önemli bir rol oynamaktadır (Konuskan, 2020).
Yağların fiziksel ve kimyasal özellikleri yapı taşı olan yağ asitlerinin kompozisyonuna bağlıdır. İçerdikleri yağ asitleri kompozisyonu yağın kullanım alanlarını, sağlıkla olan ilişkisini, stabilitesini belirlemektedir (Kayahan, 2003). Yağ asidi kompozisyonuna göre yağlar, yemeklik sıvı yağ, sabun, parfümeri ve diğer endüstri kolları gibi birçok alanda kullanılmaktadır (Karaca ve Aytaç, 2007). Yağ asidi bileşimi ve bitkisel yağların stabilitesi, dengeli bir diyette biyolojik olarak aktif bileşiklerin temel bir kaynağı olarak son yıllarda daha fazla dikkat çekmektedir (Konuskan ve ark., 2019). Yağ asitlerinin adlandırılması, içeriğindeki karbon atomu sayıları, karbon atomları arasındaki çift bağ sayıları ve karbon atomlarına bağlı hidrojenlerin pozisyonuna göre farklılık göstermektedir. Taşıdıkları bağ çeşidine göre yağ asitleri doymuş ve doymamış olmak üzere iki ana gruba ayrılmaktadır. Doymamış yağ asitleri ise tekli doymamış ve çoklu doymamış yağ asidi olarak ikiye ayrılmaktadır (Karabulut ve Yandı 2006). Doymuş yağ asitlerinin büyük çoğunluğu oda sıcaklığında katıdır ve yapısında çift bağ yoktur. Aynı zamanda, bu yağ asitleri insan vücudunda sentezlenebilmektedir. Doymuş yağ asitleri kandaki düşük yoğunluklu lipoproteinin (LDL) temizlenmesini engellemekte ve bu nedenle düşük yoğunluklu lipoprotein (LDL) halk arasında kötü kolesterol olarak bilinmektedir (Öztürk, 2014). Doymamış yağ asitleri (UFA'lar) ise, çoğunlukla cis konfigürasyonunda bir veya daha fazla çift bağa sahip alfa karboksilik asitler içeren yağ asitleri olarak isimlendirilir ve bunlar daha yüksek organizmalar için temeldir. Çoğu bitkide bulunan doymamış yağ asitleri, hem abiyotik hem de biyotik streslerle derinden ilişkili olmalarından dolayı çok önemli rolleri bulunmaktadır (Öztürk, 2014; He ve ark., 2020). Ayrıca tekli ve çoklu doymamış yağ asitleri insanlar tarafından sentezlenemediğinden diyet için gerekli yağ asitleridir. Doymamış asitlerin temel besinler olduğu bilinmektedir bu nedenle bunları yüksek miktarlarda içeren gıdaların gıda pazarında umut verici olduğu düşünülebilir (Melo ve ark., 2019; He ve ark., 2020).

Bu çalışmada badem, çörekotu, menengiç, çiya, hardal, acı kayısı çekirdeği, yerli susam, beyaz susam, keten, aspir, kanola, haşhaş, yer fıstığı ve hindistan cevizi gibi 14 farklı bitkinin tohum, çekirdek ve meyvelerinden soğuk pres yöntemiyle elde edilen sabit yağların yağ asitleri kompozisyonunun belirlenmesi amaçlanmıştır.

\section{MATERYAL ve YÖNTEM}

\section{Materyal}

Çalışmada materyal olarak badem tohumu, çörekotu tohumu, menengiç meyvesi, çiya tohumu, hardal tohumu, acı kayısı çekirdeği tohumu, yerli susam 
tohumu, beyaz susam tohumu, keten tohumu, aspir tohumu, kanola tohumu, haşhaş tohumu, yer fıstığı tohumu ve tane hindistan cevizi üretici ve aktarlardan temin edilmiştir. Bitkilerden yağların ekstraksiyonunda saatte $5 \mathrm{~kg}$ ezme kapasitesine sahip tek kafa vidalı soğuk pres (Koçmaksan, İzmir, 1.5 kw, 220 volt) kullanılmıştır. Elde edilen yağlar partiküllerden uzaklaştırmak için filtre kâğıdı ile süzülerek 10 ml'lik kahverengi cam şişelere hava boşluğu kalmayacak şekilde doldurulup $-18^{\circ} \mathrm{C}^{\prime}$ de analizlere kadar muhafaza edilmiştir.

\section{Yöntem}

Yağ Asidi Metil Esterlerinin Hazırlanması: $0.1 \mathrm{~g}$ yağ örneği, 5 ml'lik cam tüp içerisine tartılmış ve üzerine 2 $\mathrm{mL} n$-heptan ilave edilerek karıştırımıştır. Daha sonra üzerine $0.2 \mathrm{~mL} 2 \mathrm{~N}$ metanollü $\mathrm{KOH}$ eklenip, vorteks karıştırıcıda 30 sn daha karıştırılmıştır. Karışım 5000 rpm'de 10 dakika santrifüj edilmiştir. Santrifüj sonunda metil esterleri içeren üst faz, pastör pipeti yardımıyla cam viallere alınmıştır. Bu üst fazdan $1 \mu \mathrm{L}$ kadar alınıp Gaz kromatografisine enjekte edilmiştir (IOOC, 2001).

Gaz Kromatografisi (GK) Koşulları ve Yağ Asitlerinin Tanısı: Yağ asidi metil esterlerinin analizi 6850 (Agilent) gaz kromatografisi ile DB-23 (AgilentTech.) kapiler kolon kullanılarak gerçekleştirilmiştir. Kolonun uzunluğu $60 \mathrm{~m}$ ve iç çapı $0.25 \mathrm{~mm}$ 'dir. Enjeksiyon portu sıcaklığı $230{ }^{\circ} \mathrm{C}$ dedektör sıcaklığı $280{ }^{\circ} \mathrm{C}$ ve split oranı 1:50'dir. Kolon sıcaklığı, $50{ }^{\circ} \mathrm{C}$ 'den başlayarak dakikada $5^{\circ} \mathrm{C}$ artarak 230 ${ }^{\circ} C^{\prime}$ ye çıkarılmıştır. Taşıyıcı gaz olarak helyum kullanılmış ve akış hızı $1 \mathrm{~mL} d \mathrm{dk}^{\prime}$ dır. Cihaza enjekte edilen örnek miktarı $1 \mu l$ 'dir. Kromatogramdaki piklerin alıkonma süreleri, standart metil esterleri verilmek suretiyle kıyaslanarak tespit edilmiştir.

\section{Deneme deseni ve istatistik analiz}

Incelenen karakterlere ait ortalamalar ve varyans analizleri MstatC istatistik paket programıyla yapılmış; ortalamalar arasındaki farklar ise Duncan testi ile belirlenmiştir.

\section{BULGULAR ve TARTIŞMA}

Çalışmada, on dört farklı bitkinin tohum veya meyvesinden soğuk pres yöntemiyle elde edilen yağlarla ilgili yağ asidi kompozisyonlarına ait doymuş, tekli doymamış ve çoklu doymamış yağ asidi içerikleri ayrıntılı şekilde değerlendirilmesi yapılmıştır. Bu bitkilere ait dokuz adet doymuş, yedi adet tekli doymamış ve sekiz adette çoklu doymamış yağ asidi tespit edilmiştir. Soğuk pres yağ asitlerine ait parametrelerin varyans analizi (ANOVA) Çizelge 1 'de verilmiş olup, incelenen özelliklerin $\mathrm{F}$ değerleri (Yağ asidi (A)) istatistiksel olarak önemli bulunmuştur.

Çizelge 1. Soğuk pres sabit yağların yağ asidi kompozisyonlarına ait varyans analizi (ANOVA)

Table 1. Analysis of variance (ANOVA) of fatty acid compositions of cold-pressed oils

\begin{tabular}{lrrrrr}
\hline Yağ Asitleri & $\begin{array}{c}\text { Serbestlik Derecesi } \\
\text { (Tekerrür) }\end{array}$ & $\begin{array}{c}\text { Serbestlik Derecesi } \\
\text { (Yağ asidi (A)) }\end{array}$ & $\begin{array}{c}\text { F Değeri } \\
\text { (Tekerrrür) }\end{array}$ & $\begin{array}{c}\text { F Değeri } \\
\text { (Yağ asidi (A)) }\end{array}$ & Varyasyon Katsayısı \\
\hline C10:0 & 2 & 26 & 0.76 & $8209.03^{* *}$ & 6.78 \\
C12:0 & 2 & 26 & 1.62 & $3749458.44^{* *}$ & 0.33 \\
C14:0 & 2 & 26 & 8.44 & $1153504.07^{* *}$ & 0.55 \\
C15:0 & 2 & 26 & $14.15^{* *}$ & $46.43^{* *}$ & 11.30 \\
C16:0 & 2 & 26 & $14.62^{* *}$ & $15711412.90^{* *}$ & 0.02 \\
C17:0 & 2 & 26 & $9.82^{* *}$ & $3824.74^{* *}$ & 4.32 \\
C18:0 & 2 & 1.97 & $4993.51^{* *}$ & 1.10 \\
C20:0 & 26 & 26 & $5.66^{* *}$ & $884.51^{* *}$ & 5.61 \\
C22:0 & 2 & 26 & $22.03^{* *}$ & $16807.69^{* *}$ & 1.93 \\
TSAT & 2 & 26 & 2.24 & $1221057.11^{* *}$ & 0.14 \\
C14:I & 2 & 26 & $25.80^{* *}$ & $109.42^{* *}$ & 10.67 \\
C16:I & 2 & 26 & $20.54^{* *}$ & $21317719.03^{* *}$ & 0.11 \\
C15:I & 2 & 26 & $32.11^{* *}$ & $233.05^{* *}$ & 5.48 \\
C17:I & 2 & 1.87 & $139.72^{* *}$ & 16.14 \\
C18:In9c & 2 & 26 & $152.80^{* *}$ & $2922184206.97^{* *}$ & 0.00 \\
C20:I & 2 & 26 & $64.28^{* *}$ & $74207.45^{* *}$ & 0.81 \\
\hline
\end{tabular}

*,**: Sırasıyla 0.05 ve 0.01 düzeylerinde önemli olup aynı harf ile gösterilen ortalamalar arasında istatistiki olarak fark yoktur. LSD:0.22. 
Çizelge 1 (devamı). Soğuk pres sabit yağların yağ asidi kompozisyonlarına ait varyans analizi (ANOVA) Table 1 (continued). Analysis of variance (ANOVA) of fatty acid compositions of cold-pressed oils

\begin{tabular}{|c|c|c|c|c|c|}
\hline Yağ Asitleri & $\begin{array}{c}\text { Serbestlik Derecesi } \\
\text { (Tekerrür) }\end{array}$ & $\begin{array}{c}\text { Serbestlik } \\
\text { Derecesi } \\
\text { (Yă̆ asidi (A)) }\end{array}$ & $\begin{array}{l}\text { F Değeri } \\
\text { (Tekerrrür) }\end{array}$ & $\begin{array}{c}\text { F Değeri } \\
\text { (Yağ asidi }(A))\end{array}$ & $\begin{array}{l}\text { Varyasyon } \\
\text { Katsayısı }\end{array}$ \\
\hline MUFA & 2 & 26 & 0.65 & $1249302.36 * *$ & 0.08 \\
\hline C18:3n6 & 2 & 26 & $40.44^{* *}$ & $153221764.94^{* *}$ & 0.03 \\
\hline C18:3n3 & 2 & 26 & $61.60 * *$ & $256603907.30^{* *}$ & 0.03 \\
\hline C18:2n6c & 2 & 26 & 0.84 & $536411.91^{* *}$ & 0.14 \\
\hline C20:4 & 2 & 26 & 1.21 & $6.14^{* *}$ & 115.35 \\
\hline C20:5n3 & 2 & 26 & $8.18^{* *}$ & $371.75 * *$ & 10.97 \\
\hline C22:6n3 & 2 & 26 & $6.25^{* *}$ & $164.55^{* *}$ & 7.16 \\
\hline PUFA & 2 & 26 & 2.47 & $1839204.63 * *$ & 0.07 \\
\hline TUFA & 2 & 26 & 2.24 & $1221015.30 * *$ & 0.04 \\
\hline $\mathrm{P} / \mathrm{S}$ & 2 & 26 & 1.51 & $15738.29 * *$ & 0.73 \\
\hline
\end{tabular}

*,**: Sırasıyla 0.05 ve 0.01 düzeylerinde önemli olup aynı harf ile gösterilen ortalamalar arasında istatistiki olarak fark yoktur. LSD:0.22.

Çizelge 1'de soğuk pres yöntemiyle elde edilen sabit yağlara ait yağ asitleri taşıdıkları bağ çeşitlerine göre doymuş, tekli doymamış ve çoklu doymamış yağ asidi oranlarının genel değerlendirmesi yapılmıştır.

Çalışması yapılan bitkilere ait toplam doymuş yağ asidi bakımından değerlendirme yapıldığında en yüksek \%84.78 oranı ile hindistan cevizi yağından toplam doymuş yağ asidi elde edilmiştir. Doymamış yağ asitlerinin değerlendirilmesi yapıldığında, toplam doymamıs yağ asidi bakımından ise en yüksek \%91.19 oranı ile kanola yağından, tekli doymamış yağ asidi bakımından en yüksek \%67.04 oranı ile acı kayısı çekirdeği yağından, çoklu doymamış yağ asidinde ise en yüksek \%69.76 oranı ile haşhaş tohumlarından elde edilmiştir (Çizelge 2).

Çizelge 2. Soğuk pres yöntemiyle sabit yağ elde edilen bitkilere ait yağ asidi kompozisyonlarının oranları

Table 2. Proportions of fatty acid compositions of oils obtained by the cold-press method

\begin{tabular}{|c|c|c|c|c|c|}
\hline $\begin{array}{l}\text { Soğuk Pres Yöntemiyle } \\
\text { Sabit Yağ Elde Edilen } \\
\text { Bitkiler }\end{array}$ & $\begin{array}{l}\text { Toplam Doymuş } \\
\text { Yağ Asidi (TSAT) } \\
\text { (\%) }\end{array}$ & $\begin{array}{c}\text { Tekli Doymamış } \\
\text { Yağ Asidi (MUFA) } \\
\text { (\%) }\end{array}$ & $\begin{array}{l}\text { Çoklu Doymamış } \\
\text { Yağ Asidi (PUFA) } \\
\text { (\%) }\end{array}$ & $\begin{array}{l}\text { Toplam Doymamış } \\
\text { Yağ Asidi (TUFA) } \\
\text { (\%) }\end{array}$ & $\begin{array}{c}\text { Toplam Doymamış Yağ Asidi } \\
\text { / Toplam Doymuş Yağ Asidi } \\
\text { (P/S oranı) }\end{array}$ \\
\hline Badem tohumu & $13.33 \mathrm{k}$ & $64.75 b$ & $21.92 \mathrm{k}$ & $86.67 \mathrm{~d}$ & $6.50 \mathrm{~d}$ \\
\hline Çörekotu tohumu & $21.09 \mathrm{~d}$ & $24.41 \mathrm{j}$ & $54.51 \mathrm{~d}$ & $78.91 \mathrm{k}$ & 3.74 I \\
\hline Menengiç meyvesi & $33.82 b$ & $50.12 \mathrm{e}$ & $16.06 \mathrm{~m}$ & $66.18 \mathrm{~m}$ & $2.01 \mathrm{k}$ \\
\hline Çiya tohumu & $16.06 \mathrm{~h}$ & $18.62 I$ & $65.33 c$ & $83.94 \mathrm{~g}$ & $5.23 \mathrm{~g}$ \\
\hline Hardal tohumu & 10.431 & $41.93 \mathrm{f}$ & $47.64 \mathrm{f}$ & $89.58 \mathrm{c}$ & $8.60 \mathrm{c}$ \\
\hline $\begin{array}{l}\text { Acı Kayısı Çekirdeği } \\
\text { tohumu }\end{array}$ & $9.12 \mathrm{~m}$ & $67.04 \mathrm{a}$ & $23.84 j$ & $90.88 \mathrm{~b}$ & $9.96 \mathrm{~b}$ \\
\hline Yerli Susam tohumu & $21.86 \mathrm{c}$ & $38.27 \mathrm{~g}$ & $39.88 \mathrm{~h}$ & 78.141 & $3.58 \mathrm{j}$ \\
\hline Beyaz Susam tohumu & 20.87 e & $37.65 \mathrm{~h}$ & $41.48 \mathrm{~g}$ & $79.13 \mathrm{j}$ & I I.79 \\
\hline Keten tohumu & $13.93 \mathrm{j}$ & $19.17 \mathrm{k}$ & $66.90 \mathrm{~b}$ & $86.07 \mathrm{e}$ & $6.18 \mathrm{e}$ \\
\hline Aspir tohumu & I5.09 & $35.74 \mathrm{~h}$ & $49.17 \mathrm{e}$ & $84.91 \mathrm{f}$ & $5.63 \mathrm{f}$ \\
\hline Kanola tohumu & $8.81 n$ & $64.22 \mathrm{c}$ & 26.97 I & $91.19 \mathrm{a}$ & $10.35 \mathrm{a}$ \\
\hline Haşhaş tohumu & $17.27 \mathrm{f}$ & $12.96 n$ & $69.76 \mathrm{a}$ & 82.73 । & $4.79 \mathrm{~h}$ \\
\hline Yer Fıstığı tohumu & $17.12 \mathrm{~g}$ & $61.13 \mathrm{~d}$ & $21.75 I$ & $82.88 \mathrm{~h}$ & $4.84 \mathrm{~h}$ \\
\hline Tane Hindistan Cevizi & 84.78 a & $15.22 \mathrm{~m}$ & $0.00 n$ & $15.22 \mathrm{n}$ & 0.181 \\
\hline
\end{tabular}

*,**: Sırasıyla 0.05 ve 0.01 düzeylerinde önemli olup aynı harf ile gösterilen ortalamalar arasında istatistiki olarak fark yoktur. LSD: 0.22 .

Bitkisel yağlarda aranan kalite özelliklerinden birisi de doymamış yağ asitlerinin toplam miktarının, doymuş yağ asitlerinin toplam miktarına olan oranıdır. Bu oran $\mathrm{P} / \mathrm{S}$ oranı olarak ifade edilmekte olup, miktarı sayısal bir değerdir (Arıoğlu ve ark.,2012). Soğuk pres yöntemiyle yağları çıkarılan bitkilere ait $\mathrm{P} / \mathrm{S}$ değeri Çizelge 1 'de 
verilmiştir. $\mathrm{Bu}$ bitkilere ait $\mathrm{P} / \mathrm{S}$ değerleri $0.02-10.43$ arasında değişmektedir. Bitkilerin $\mathrm{P} / \mathrm{S}$ değeri arasında değerlendirme yapıldığında en yüksek sırasıyla 10.35 ile Kanola bitkisinden ve 9.96 ile acı kayısı çekirdeği yağından elde edilmiştir (Çizelge 1 ). Soya çeşitlerinin $\mathrm{P} / \mathrm{S}$ değeri incelemesinden, çeşitlerin $\mathrm{P} / \mathrm{S}$ değerlerinin 4.906.25 arasında değişim gösterdiğini bildirmiştir (Arıoğlu ve ark.,2012). Dünya Sağlık Örgütü'ne göre yağların gıda olarak tüketilebilir olması için $\mathrm{P} / \mathrm{S}$ değerinin 2 veya daha üzerinde olması gerekmektedir (Dağhan ve Vardin, 2019). Bu çalışmadaki yağların $P / S$ değerleri incelendiğinde sadece Hindistan Cevizi yağı $0.18 \mathrm{P} / \mathrm{S}$ değerleriyle, DSÖ standartlarının altında kalarak gıda olarak tüketilebilir yağ değerinin altında kalmaktadır. Diğer yağlar ise DSÖ göre gıda olarak tüketilebilir yağ sınıfına girmektedir.

\section{Doymuş yağ asitleri (SAT)}

Soğuk pres yöntemiyle yağ elde edilen bitkilere ait doymuş yağ asitlerinin Çizelge 3 'de değerlendirilmesi yapılmıştır. Toplam dokuz adet doymuş yağ asidinin bitkilere göre dağılımı incelendiğinde; Karpik asit (C10:0) yönünden en yüksek 7.098, Laurik asit (C12:0) yönünden en yüksek 53.540 ile ve Miristik asit (C14:0) yönünden en yüksek 16.339 ile Hindistan cevizinde gerçekleşmiştir. Ayrıca Pentadekonoik asit (C15:0) yönünden en yüksek 0.053 ile Çörek otu, Palmitik asit (C16:0) yönünden 32.452 ile Menengiç, Heptadekonoik asit (C17:0) yönünden en yüksek 1.007 ile Hardal yağı, Stearik asit (C18:0) yönünden en yüksek 5.367 ile Yerli Susam, Arakhidik asit (C20:0) yönünden 0.645 ile yer fıstığından ve Behenik asit (C22:0) yönünden en yüksek 0.297 ile Hardal yağından elde edilmiştir (Çizelge 3 ). Doymuş yağ asitleri içerisinde en yüksek oran palmitik asit (C16:0) ve stearik asit (C18:0) gelmektedir. Palmitik asit (C16:0) oranın bakımından en düşük 5.095 ile Hindistan cevizi ve en yüksek 32.452 ile Menegiç yağından elde edilmiştir. Stearik asit (C18:0) bakımından en düşük 1.340 ile acı kayısı çekirdeği yağı ve en yüksek 5.367 ile Yerli Susam yağından elde edilmiştir. Diğer doymuş yağlar içerisinde Karpik asit (C10:0), Laurik asit (C12:0) ve miristik asit (C14:0) en yüksek Hindistan cevizinde gerçekleşmiştir (Çizelge 3).

Çizelge 3. Soğuk pres yöntemiyle sabit yağ elde edilen bitkilere ait doymuş yağ asidi değerleri

Table 3. Saturated fatty acid values of oils obtained by the cold-press method

\begin{tabular}{|c|c|c|c|c|c|c|c|c|c|}
\hline $\begin{array}{l}\text { Soğuk Pres Yöntemiyle } \\
\text { Sabit Yağ Elde Edilen } \\
\text { Bitkiler }\end{array}$ & 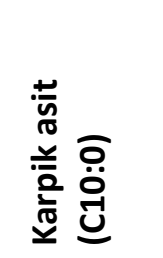 & 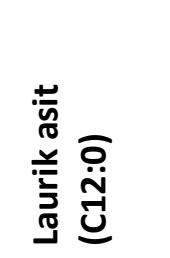 & 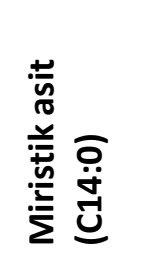 & 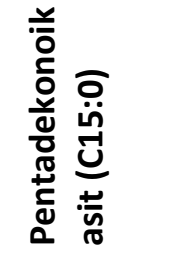 & 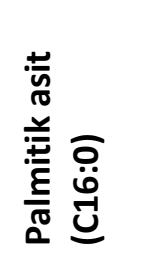 & 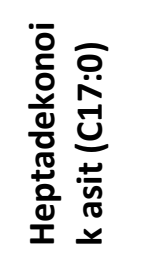 & 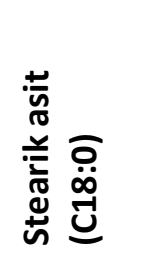 & 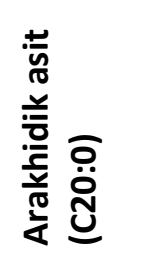 & 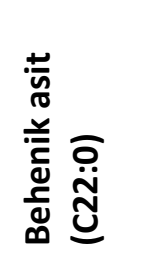 \\
\hline Badem tohumu & $0.028 \mathrm{bc}$ & $0.022 \mathrm{de}$ & $0.014 \mathrm{~h}$ & $0.029 a-c$ & 11.607 I & $0.075 \mathrm{e}$ & $1.525 \mathrm{k}$ & $0.049 \mathrm{e}$ & 0.013 ef \\
\hline Çörekotu tohumu & $0.015 \mathrm{c}$ & $0.012 \mathrm{e}$ & $0.284 \mathrm{~b}$ & $0.053 a$ & $16.877 \mathrm{~b}$ & 0.062 ef & $3.272 \mathrm{~d}$ & $0.217 c$ & 0.018 ef \\
\hline Menengiç meyvesi & $0.023 b c$ & $0.017 \mathrm{e}$ & $0.150 \mathrm{e}$ & $0.022 b c$ & $32.452 \mathrm{a}$ & $0.131 \mathrm{~d}$ & $1.725 \mathrm{j}$ & $0.194 c d$ & 0.102 c \\
\hline Çiya tohumu & $0.012 c$ & $0.092 b$ & 0.130 ef & $0.036 a b$ & $11.892 \mathrm{~h}$ & $0.222 c$ & $2.966 \mathrm{f}$ & $0.020 f$ & $0.021 \mathrm{ef}$ \\
\hline Hardal tohumu & $0.039 \mathrm{bc}$ & $0.043 \mathrm{~cd}$ & $0.189 \mathrm{~d}$ & $0.038 a b$ & 6.7101 & $1.007 \mathrm{a}$ & $2.141 \mathrm{~h}$ & 0.067 e & $0.297 a$ \\
\hline $\begin{array}{l}\text { Acı Kayısı Çekirdeği } \\
\text { tohumu }\end{array}$ & $0.028 b c$ & $0.021 \mathrm{de}$ & $0.048 \mathrm{~g}$ & $0.009 \mathrm{c}$ & $7.642 \mathrm{k}$ & $0.032 \mathrm{~g}$ & $1.340 \mathrm{I}$ & $0.009 \mathrm{f}$ & $0.006 f$ \\
\hline Yerli Susam tohumu & $0.019 \mathrm{bc}$ & $0.010 \mathrm{e}$ & $0.053 \mathrm{~g}$ & $0.021 b c$ & $16.197 \mathrm{c}$ & $0.044 \mathrm{fg}$ & 5.367 a & $0.009 \mathrm{f}$ & 0.014 ef \\
\hline Beyaz Susam tohumu & $0.022 b c$ & $0.019 \mathrm{de}$ & $0.045 \mathrm{~g}$ & $0.034 a-c$ & $15.535 d$ & 0.057 ef & $4.992 b$ & $0.305 \mathrm{~b}$ & $0.153 b$ \\
\hline Keten tohumu & $0.018 c$ & $0.015 \mathrm{e}$ & $0.109 \mathrm{f}$ & $0.039 a b$ & $9.743 j$ & $0.074 \mathrm{e}$ & $4.070 \mathrm{c}$ & $0.186 d$ & 0.024 ef \\
\hline Aspir tohumu & $0.018 c$ & 0.019 de & $0.247 c$ & $0.037 a b$ & $12.715 \mathrm{~g}$ & $0.047 \mathrm{fg}$ & $2.290 \mathrm{~g}$ & $0.216 \mathrm{c}$ & 0.014 ef \\
\hline Kanola tohumu & $0.023 \mathrm{bc}$ & $0.063 \mathrm{c}$ & $0.126 \mathrm{f}$ & $0.038 a b$ & $6.355 \mathrm{~m}$ & $0.049 \mathrm{fg}$ & $2.079 \mathrm{~h}$ & $0.310 \mathrm{~b}$ & $0.059 d$ \\
\hline Haşhaş tohumu & $0.032 b c$ & $0.044 \mathrm{~cd}$ & $0.118 \mathrm{f}$ & $0.027 b c$ & $14.738 \mathrm{e}$ & $0.066 \mathrm{ef}$ & $2.230 \mathrm{~g}$ & $0.064 \mathrm{e}$ & 0.017 ef \\
\hline Yer Fıstığı tohumu & $0.101 b$ & $0.022 \mathrm{de}$ & $0.057 \mathrm{~g}$ & $0.013 b c$ & $13.464 \mathrm{f}$ & $0.140 \mathrm{~d}$ & $3.174 \mathrm{e}$ & $0.645 a$ & $0.009 \mathrm{f}$ \\
\hline Tane Hindistan Cevizi & 7.098 a & $53.540 \mathrm{a}$ & $16.339 \mathrm{a}$ & $0.009 c$ & $5.095 n$ & $0.301 b$ & $1.914 \mathrm{I}$ & $0.191 d$ & $0.038 \mathrm{de}$ \\
\hline
\end{tabular}

\section{Doymamış yağ asitleri}

Tekli doymamış yağ asitleri (MUFA)

Soğuk pres yöntemiyle elde edilen yağlar tekli doymamış yağ asitleri bakımından incelendiğinde, Miristoleik asit (C14:1) bakımından en yüksek 0.036 ile çiya yağından, Palmitoleik asit (C16:1) bakımından en yüksek 12.607 ile 
menengiç yağından, Pentadekanoik asit (C15:1) yönünden en yüksek 0.034 ile badem yağından, Heptadekanoik asit (C17:1) yönünden 0.545 ile aspir yağından, Oleik asit (C18:1n9c) yönünden en yüksek
65.990 ile acı kayısı çekirdeği yağından ve Gadoleik asit (C20:1) yönünden en yüksek 0.307 ile çörek otu yağından elde edilmiştir (Çizelge 4).

Çizelge 4. Soğuk pres yöntemiyle sabit yağ elde edilen bitkilere ait tekli doymamış yağ asidi değerleri

Table 4. Monounsaturated fatty acid values of plants obtained by the cold-press method

\begin{tabular}{|c|c|c|c|c|c|c|}
\hline $\begin{array}{l}\text { Soğuk Pres Yöntemiyle Sabit Yağ } \\
\text { Elde Edilen Bitkiler }\end{array}$ & 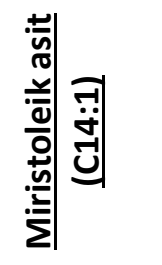 & 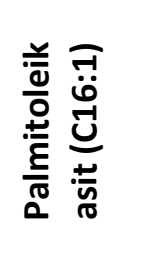 & 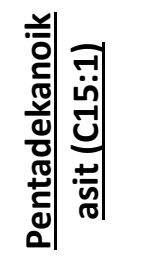 & 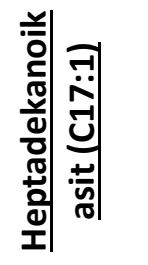 & 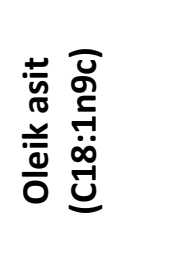 & 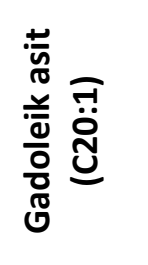 \\
\hline Badem tohumu & $0.008 \mathrm{~b}$ & $0.659 c$ & $0.034 \mathrm{a}$ & $0.104 \mathrm{e}$ & $63.776 \mathrm{~b}$ & $0.007 \mathrm{~h}$ \\
\hline Çörekotu tohumu & $0.009 \mathrm{~b}$ & $0.288 \mathrm{~d}$ & $0.022 \mathrm{a}$ & $0.063 \mathrm{fg}$ & $23.321 \mathrm{j}$ & 0.307 a \\
\hline Menengiç meyvesi & $0.011 \mathrm{~b}$ & 12.607 a & $0.008 \mathrm{a}$ & $0.127 \mathrm{~d}$ & 39.748 e & $0.004 \mathrm{~h}$ \\
\hline Çiya tohumu & $0.036 a$ & $0.123 \mathrm{f}$ & $0.013 a$ & $0.016 \mathrm{~h}$ & $17.230 ।$ & $0.006 \mathrm{~h}$ \\
\hline Hardal tohumu & $0.011 b$ & $0.102 \mathrm{f}$ & $0.015 \mathrm{a}$ & $0.282 \mathrm{~b}$ & $39.673 \mathrm{e}$ & $0.014 \mathrm{gh}$ \\
\hline Acı Kayısı Çekirdeği tohumu & $0.012 b$ & $0.034 \mathrm{~h}$ & $0.012 \mathrm{a}$ & $0.153 c$ & $65.990 \mathrm{a}$ & $0.076 \mathrm{e}$ \\
\hline Yerli Susam tohumu & $0.007 \mathrm{~b}$ & $0.068 \mathrm{~g}$ & 0.009 a & $0.044 \mathrm{~g}$ & $37.754 \mathrm{~g}$ & $0.251 b$ \\
\hline Beyaz Susam tohumu & $0.008 \mathrm{~b}$ & 0.223 e & $0.011 \mathrm{a}$ & $0.039 \mathrm{~g}$ & $37.030 \mathrm{~h}$ & $0.048 \mathrm{f}$ \\
\hline Keten tohumu & $0.011 b$ & $0.121 \mathrm{f}$ & $0.011 \mathrm{a}$ & $0.058 \mathrm{~g}$ & $19.012 \mathrm{k}$ & $0.121 d$ \\
\hline Aspir tohumu & $0.012 b$ & $0.689 \mathrm{~b}$ & $0.022 \mathrm{a}$ & $0.545 \mathrm{a}$ & 35.538 । & $0.012 \mathrm{gh}$ \\
\hline Kanola tohumu & $0.005 b$ & $0.294 d$ & $0.014 \mathrm{a}$ & 0.082 ef & $61.950 \mathrm{c}$ & $0.014 \mathrm{gh}$ \\
\hline Haşhaş tohumu & $0.010 \mathrm{~b}$ & 0.219 e & $0.010 \mathrm{a}$ & $0.057 \mathrm{~g}$ & $12.731 \mathrm{n}$ & $0.016 \mathrm{gh}$ \\
\hline Yer Fıstığı tohumu & $0.007 \mathrm{~b}$ & $0.115 f$ & 0.009 a & 0.090 e & $59.406 \mathrm{~d}$ & $0.036 \mathrm{fg}$ \\
\hline Tane Hindistan Cevizi & $0.015 a b$ & 0.0081 & $0.015 \mathrm{a}$ & $0.087 \mathrm{e}$ & $15.076 \mathrm{~m}$ & $0.178 \mathrm{c}$ \\
\hline
\end{tabular}

* ,**: Sırasıyla 0.05 ve 0.01 düzeylerinde önemli olup aynı harf ile gösterilen ortalamalar arasında istatistiki olarak fark yoktur. LSD: 0.22 .

\section{Çoklu doymamış yağ asitleri (PUFA)}

Soğuk pres yöntemiyle elde edilen yağlar, çoklu doymamış yağ asitleri bakımından incelendiğinde, $r$ Linolenik asit (C18:3n6) yönünden en yüksek 30.504 ile Keten yağından, $\alpha$-Linolenik asit (C18:3n3) yönünden en yüksek 20.214 ile Keten yağından, Linoleik asit (C18:2n6) yönünden en yüksek 68.526 ile Haşhaş yağından, Araşidonik asit (C20:4) bakımından en yüksek 0.391 ile Yerfıstığı yağından, Eikosapentaenoik asit (C20:5n3) bakımından en yüksek 0.170 ile Hardal yağından, Dokosaheksaenoik asit (C22:6n3) bakımından en yüksek 0.032 ile Aspir yağından elde edilmiştir (Çizelge 5). 
Çizelge 5. Soğuk pres yöntemiyle sabit yağ elde edilen bitkilere ait çoklu doymamış yağ asidi değerleri Table 5. Polyunsaturated fatty acid values of oils obtained by the cold-press method

\begin{tabular}{|c|c|c|c|c|c|c|}
\hline Soğuk Pres Yöntemiyle Sabit Yağ Elde Edilen Bitkiler & 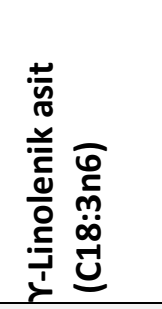 & 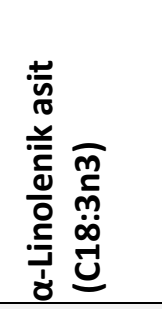 & 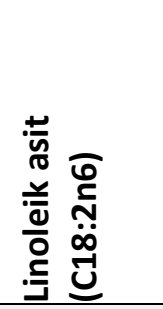 & 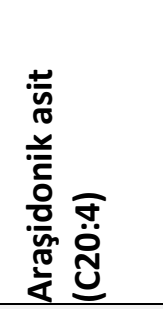 & 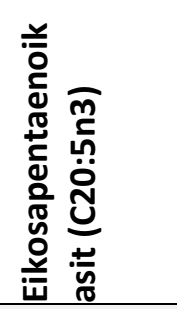 & 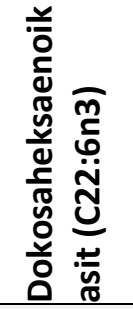 \\
\hline Badem tohumu & $0.052 j$ & $0.053 \mathrm{hl}$ & 21.589 । & $0.006 \mathrm{c}$ & $0.017 \mathrm{~d}-\mathrm{f}$ & $0.016 \mathrm{a}$ \\
\hline Çörekotu tohumu & $0.292 \mathrm{~g}$ & $0.149 \mathrm{f}$ & $52.089 \mathrm{c}$ & $0.014 \mathrm{c}$ & $0.007 \mathrm{f}$ & $0.025 \mathrm{a}$ \\
\hline Menengiç meyvesi & $0.512 \mathrm{e}$ & $0.152 f$ & 16.444 I & $0.006 \mathrm{c}$ & $0.007 \mathrm{f}$ & $0.009 a$ \\
\hline Çiya tohumu & $0.029 \mathrm{k}$ & $0.024 \mathrm{j}$ & $60.455 b$ & $0.024 \mathrm{c}$ & $0.019 \mathrm{~d}-\mathrm{f}$ & $0.012 \mathrm{a}$ \\
\hline Hardal tohumu & $11.632 b$ & $3.692 \mathrm{~b}$ & $29.649 \mathrm{~g}$ & $0.230 \mathrm{ab}$ & 0.170 a & $0.013 a$ \\
\hline Acı Kayısı Çekirdeği tohumu & $0.062 \mathrm{j}$ & $0.075 \mathrm{gh}$ & $23.462 \mathrm{~h}$ & $0.012 c$ & 0.012 ef & $0.014 \mathrm{a}$ \\
\hline Yerli Susam tohumu & $0.313 \mathrm{~g}$ & $0.313 \mathrm{e}$ & $39.344 \mathrm{f}$ & $0.032 c$ & 0.013 ef & $0.006 a$ \\
\hline Beyaz Susam tohumu & $0.269 \mathrm{~h}$ & $0.097 \mathrm{~g}$ & 40.803 e & $0.030 \mathrm{c}$ & 0.013 ef & $0.009 a$ \\
\hline Keten tohumu & $30.504 \mathrm{a}$ & 20.214 a & $15.639 \mathrm{~m}$ & $0.029 c$ & 0.012 ef & $0.011 \mathrm{a}$ \\
\hline Aspir tohumu & 0.113 । & $0.132 \mathrm{f}$ & $48.893 d$ & $0.022 \mathrm{c}$ & $0.028 c-f$ & $0.032 \mathrm{a}$ \\
\hline Kanola tohumu & $6.762 \mathrm{c}$ & $1.472 \mathrm{c}$ & $17.788 \mathrm{k}$ & $0.086 \mathrm{bc}$ & 0.035 cde & $0.009 a$ \\
\hline Haşhaş tohumu & $0.477 \mathrm{f}$ & 0.037 j & 68.526 a & $0.007 \mathrm{c}$ & $0.040 \mathrm{~cd}$ & $0.016 a$ \\
\hline Yer Fıstığı tohumu & $0.791 d$ & $0.603 d$ & $21.138 \mathrm{j}$ & $0.391 \mathrm{a}$ & $0.050 \mathrm{bc}$ & $0.028 a$ \\
\hline Tane Hindistan Cevizi & $0.248 \mathrm{~h}$ & $0.039 \mathrm{ij}$ & $0.348 n$ & $0.044 \mathrm{c}$ & $0.066 \mathrm{~b}$ & $0.009 a$ \\
\hline
\end{tabular}

${ }^{*},{ }^{* *}$ : Sırasıyla 0.05 ve 0.01 düzeylerinde önemli olup aynı harf ile gösterilen ortalamalar arasında istatistiki olarak fark yoktur. LSD: 0.22 .

Çoklu doymamış yă̆ asitlerinin (PUFA) fizyolojik faydaları vardır ve temel beslenme işlevlerine ek olarak kronik hastalık riskini azaltabilirler. Bu fonksiyonel PUFA'lar membranlara esneklik, akışkanlık ve seçici geçirgenlik özellikleri kazandırır ve sonuç olarak insan sağlığı için yüksek fizyolojik ve terapötik öneme sahiptir (Bellou ve ark., 2016). Soğuk pres yağların yağ asitleri kompozisyonu ile ilgili yapılan çalışmalara bakıldığında, yapılan çalışma Badem (Balta, 2013), Çörek otu (Gümüş ve Çelenk, 2017), Menegiç (Kaya ve Özer, 2015; Pelvan ve Demirtaş, 2018), Çiya (Bodoira ve ark., 2017), Hardal (Gıdık, 2016), Acı Kayısı çekirdeği (Yücel Sengün ve ark., 2021), Keten (İşleroğlu ve ark., 2005), Susam (Yakar ve ark., 2021), Aspir (Arslan ve Culpan, 2020)., Kanola (Gıdık ve Önemli, 2019), Haşhaş (Şengün ve ark., 2020), Yer fıstığı (Ferrin ve ark., 2018) ve Hindistan cevizi (Medeiros ve ark., 2020; Rajesh ve ark., 2021) yağları ilgili çalışmalara benzerlik göstermekle birlikte yağ asitleri kompozisyonu bitki türlerine özgü bazı yağ asitlerinde farklılıklar göstermektedir. Yağ asitleri kompozisyonu çeşitli fizyolojik, ekolojik ve kültürel faktörlerin etkisi altında kaldığı için sürekli sabit değildir ve az çok değişebilmektedir.

Sonuç olarak, çalışmada Badem, Çörekotu, Menengiç, Çiya, Hardal, Acı Kayısı Çekirdeği, Yerli Susam, Beyaz Susam, Keten, Aspir, Kanola, Haşhaş, Yer Fıstığı ve Hindistan Cevizi bitkilerinin tohum ve meyvelerinden soğuk pres yöntemiyle elde edilen sabit yağların yağ asidi kompozisyonları belirlenmiştir. En yüksek toplam doymuş ve doymamış yağ asidi miktarı sırasıyla Hindistan cevizi ve Kanola yağında belirlenmiştir. En yüksek tekli doymamış ve çoklu doymamış yağ asidi içerikleri ise sırasıyla Acı Kayısı çekirdeği ve Haşhaş yağında tespit edilmiştir. Hindistan Cevizi yağı $P / S$ değeri bakımından DSÖ standartlarının altında kalarak direkt gıda olarak tüketilemez sınıfına girmektedir. Incelenen diğer soğuk pres yağların, dengeli bir yağ asitleri kompozisyonuna sahip olmasından dolayı gerek yemeklik yağ sanayi açığının kapatılması gerekse sağlık için yararları bakımından yemeklik olarak kullanılabilir yağlar arasında olabileceği sonucuna varılmıştır.

\section{ÖZET}

Amaç: Bu çalışmanın amacı, badem, çörekotu, menengiç, çiya, hardal, acı kayısı çekirdeği, yerli susam, beyaz susam, teten, aspir, kanola, haşhaş, yer fıstığı ve tane hindistan cevizi tohumlarından soğuk pres yöntemiyle elde edilen sabit yağların yağ asidi kompozisyonlarını belirlemektir.

Yöntem ve Bulgular: Bitkilerden sabit yağların ekstraksiyonunda saatte $5 \mathrm{~kg}$ ezme kapasitesine sahip tek kafa vidalı soğuk pres (Koçmaksan, İzmir, 1.5 kw, 220 volt) kullanılmıştır. Elde edilen yağlar, içindeki 
partiküllerden uzaklaştırmak için, filtre kâğıdı ile süzülerek 10 ml'lik kahverengi cam şişelere hava boşluğu kalmayacak şekilde doldurulup, $-18^{\circ} \mathrm{C}^{\prime}$ de analizlere kadar muhafaza edilmiştir. Çalışmada ele alınan bitkilerin sabit yağları, yağ asidi kompozisyonu bakımından değerlendirildiğinde, dokuz adet doymuş, altı adet tekli doymamış ve yedi adet çoklu doymamış yağ asidi içerdiği tespit edilmiştir. En yüksek toplam doymuş yağ asidi \%84.78 oranı ile hindistan cevizi yağından elde edilmiştir. En yüksek toplam doymamış yağ asidi içeriği \%91.19 oranı ile kanola yağından, en yüksek tekli doymamış yağ asidi içeriği \%67.04 oranı ile acı kayısı çekirdeği yağından, en yüksek çoklu doymamış yağ asidi içeriği ise $\% 69.76$ oranı ile Haşhaş tohumlarından elde edilmiştir. Soğuk pres yöntemiyle yağları çıkarılan bitkilere ait $P$ (çoklu doymamış yağ asitleri) / $\mathrm{S}$ (doymuş yağ asitleri) değerleri 0.02-10.43 arasında değişmektedir. Yağların en yüksek $\mathrm{P} / \mathrm{S}$ değeri sırasıyla \%10.35 ile kanola ve \%9.96 ile acı kayısı çekirdeği yağından elde edilmiştir.

Genel Yorum: Hindistan cevizi yağı $P / S$ değeri bakımından Dünya Sağlık Örgüt (DSÖ) standartlarının altında kalarak direkt gıda olarak tüketilemez sınıfına girmektedir. İncelenen diğer soğuk pres yağların, dengeli bir yağ asitleri kompozisyonuna sahip olmasından dolayı gerek yemeklik yağ sanayi açığının kapatılması gerekse sağlık için yararları bakımından yemeklik olarak kullanılabilir yağlar arasında olabileceği sonucuna varılmıştır.

Çalışmanın Önemi ve Etkisi: Sabit yağlar, yağ asidi kompozisyonlarına göre, yemeklik sıvı yağ, sabun, parfümeri ve diğer endüstri kolları gibi birçok alanda kullanılmaktadır. Bu çalışmada, soğuk pres yöntemiyle elde edilen sabit yağların kimyasal değerlerini tek bir çalışmada birleştirerek, araştırmacılar için kolay veriye ulaşııması sağlanmaya çalışıımıştır.

Anahtar Kelimeler: MUFA, PUFA, SAT, soğuk pres, yağ asidi.

\section{ÇIKAR ÇATIŞMA BEYANI}

Makale yazarları aralarında herhangi bir çıkar çatışması olmadığını beyan ederler.

\section{ARAŞTIRMACILARIN KATKI ORANI BEYANI}

Yazarlar makaleye eşit oranda katkı sağlamış olduklarını beyan ederler.

\section{KAYNAKLAR}

Altan A, Kola O (2009) Yağ işleme teknolojisi. Bizim Büro Yayınevi, $230 \mathrm{~s}$.
Arıoğlu H, Özyurtseven S, Güllüoğlu L (2012) İkinci ürün koşullarında yetiştirilen bazı soya [Glycine max (L.) Merr] çeşitlerinin yă verimi ile yağ asitleri içeriklerinin belirlenmesi-II. Çukurova Üniversitesi Ziraat Fakültesi Dergisi 27(2): 1-10.

Arslan B, Culpan E (2020) Melezleme ile geliştirilmiş bazı aspir (Carthamus tinctorius L.) genotiplerinin tarımsal ve teknolojik özelliklerinin belirlenmesi. Yüzüncü Yıl Üniversitesi Tarım Bilimleri Dergisi 30(4): 742-750.

Asil H (2020) Soğuk sıkım (pres) yöntemiyle elde edilen yağlar ve fitoterapik özellikleri, güncel fitoterapi ve geleneksel tıbbi bitkiler. Nobel Tip Kitabevleri 86-96.

Asil H, Göktürk E (2020) Uçucu yağ elde etmede modern ekstraksiyon yöntemleri, güncel fitoterapi ve geleneksel tibbi bitkiler. Nobel Tip Kitabevleri 97-104.

Balta MF (2013) Farklı iç tadı ve oluşumuna sahip badem (Prunus amygdalus Batsch) genotiplerinde yağ asitlerinin belirlenmesi. Iğdır Üniversitesi Fen Bilimleri Enstitüsü Dergisi 3(1): 17-24.

Bellou S, Triantaphyllidou IE, Aggeli D, Elazzazy AM, Baeshen MN, Aggelis G (2016) Microbial oils as food additives: recent approaches for improving microbial oil production and its polyunsaturated fatty acid content. Current opinion in Biotechnology 37: 24-35.

Bodoira RM, Penci MC, Ribotta PD, Martínez ML (2017) Chia (Salvia hispanica L.) oil stability: Study of the effect of natural antioxidants. LWT 75: 107-113.

Bozdoğan Konuşkan D (2020) Minor bioactive lipids in cold pressed oils, Yayın Elsevier, Academic Press, Bölüm Sayfaları:7 -14. (Cold Pressed Oils: Green Technology, Bioactive Compounds, Functionality, and Applications, Editör:Mohamed Fawzy Ramadan, Basım sayısı:1, Sayfa sayısı:746.

Chandra S, Kumar M, Dwivedi P, Shinde LP (2020) Functional and nutritional health benefit of coldpressed oils. Journal of Agriculture and Ecology 9: 2129.

Dağhan Ş, Vardin H (2019) Şanlıurfa biber tohumu yağının yağ asitleri kompozisyonu ve mineral içeriğinin belirlenmesi. Harran Üniversitesi Mühendislik Dergisi 4(3): 49-57.

Dogruer I, Uyar HH, Uncu O, Ozen B (2021) Prediction of chemical parameters and authentication of various cold pressed oils with fluorescence and mid-infrared spectroscopic methods. Food Chemistry 345: 128815.

Duran DÖ, Benderli ŞA (2020) Comparison physicochemical properties of hexane extracted aniseed oil from cold press extraction residue and cold press aniseed oil. International Journal of Nutrition and Food Engineering 14(9): 113-116. 
Gıdık B (2016) Trakya bölgesi florasındaki yabani hardal (Sinapis sp.) genotiplerinin moleküler ve morfolojik karakterizasyonu tarla koşullarındaki verimi ile kalite unsurlarının değerlendirilmesi. Namik Kemal Üniversitesi Fen Bilimleri Enstitüsü, Doktora Tezi, s:235.

Gidik B, Önemli F (2019) Brassica juncea, Brassica napus, Sinapsis alba ve Camelina sativa' nın yağ içeriği ve yağ asitleri kompozisyonunun belirlenmesi. Bahçe 48(2): 65-72.

Gürpınar GÇ, Geçgel Ü,Taşan M (2011) Soğuk presyon tekniği ile üretilen bitkisel yağların özellikleri ve sağlık üzerine etkileri. 7. Gıda Mühendisliği Kongresi, Ankara.

Gümüş PZ, Çelenk VU (2017) A case study on profile investigation of cold-pressed black cumin seed oil produced in Turkey. Hacettepe Journal of Biology and Chemistry 45(4): 475-484.

Ferrin FA, Yildiz R, Arioğlu HH (2018) Osmaniye koşullarına uygun yeni yerfıstığı çeşitleri ile bunların önemli tarımsal ve kalite özelliklerinin belirlenmesi. Tarim ve Doga Dergisi 21(6): 825.

He M, Qin CX, Wang X, Ding NZ (2020) Plant unsaturated fatty acids: Biosynthesis and regulation. Frontiers in Plant Science 11: 390.

Karabulut HA, Yandı i (2006) Su ürünlerindeki omega-3 yağ asitlerinin önemi ve sağlık üzerine etkisi. Ege Üniv. Su Ürünleri Derg. 23(1/3): 339-342.

Karaca E, Aytaç S (2007) Yağ bitkilerinde yağ asitleri kompozisyonu üzerine etki eden faktörler. Anadolu Tarım Bilimleri Dergisi 22(1): 123-131.

Kaya F, Özer A (2015) Characterization of extracted oil from seeds of terebinth (Pistacia terebinthus L.) growing wild in Turkey. Turkish Journal of Science and Technology 10(1): 49-57.

Kayahan M (2003) Yağ kimyası. ODTÜ Yayıncılık, Ankara. $220 \mathrm{~s}$.

Konuskan DB, Arslan M, Oksuz A (2019) Physicochemical properties of cold pressed sunflower, peanut, rapeseed, mustard and olive oils grown in the Eastern Mediterranean region. Saudi Journal of Biological Sciences 26(2): 340-344.

Konuşkan DB (2020) Minor bioactive lipids in cold pressed oils. In Cold Pressed Oils. Academic Press. pp. 7-14.

Ibrahim FM, Attia HN, Maklad YAA, Ahmed KA, Ramadan MF (2017) Deney hayvanlarında soğuk preslenmiş bazı yağların biyokimyasal karakterizasyonu, antienflamatuvar özellikleri ve ülserojenik özellikleri. Farmasötik Biyoloji 55(1): 740-748.

IOOC (2001) International olive oil council, method of analysis, preparation of the fatty acid methyl esters from olive oil and olive pomace oil. COI/T, 20/Doc.No.24.

Işleroğlu H, Yıldırım Z, Yıldırım M (2005) Fonksiyonel bir gıda olarak keten tohumu. GOÜ. Ziraat Fakültesi Dergisi 22(2): 23-30.

Medeiros de Azevedo W, Ferreira Ribeiro de Oliveira L, Alves Alcântara M, Tribuzy de Magalhães Cordeiro AM, Florentino da Silva Chaves Damasceno KS, Kelly de Araújo N, Sousa Junior FCD (2020) Physicochemical characterization, fatty acid profile, antioxidant activity and antibacterial potential of cacay oil, coconut oil and cacay butter. PloS One 15(4): e0232224.

Melo E, Michels F, Arakaki D, Lima N, Gonçalves D, Cavalheiro L, Nascimento V (2019) First study on the oxidative stability and elemental analysis of babassu (Attalea speciosa) edible oil produced in Brazil using a domestic extraction machine. Molecules 24(23): 4235.

Öztürk MO (2014) Esansiyel yağ asitlerinin insan metabolizması ve beslenmesi üzerine etkileri. Kocatepe Vet. J. 7(2): 37-40.

Pelvan E, Demirtas I (2018) Türkiye'de yetişen bıttım (Pistacia terebinthus L.) ve fistık (Pistacia vera) yağlarinin yağ asidi, sterol, tokol kompozisyonlari, toplam fenolik madde miktarlari ve antioksidan aktivitelerinin belirlenmesi. Gıda 43(3): 384-392.

Rajesh K, Devan PK, GK BK (2021) Parametric optimization and biodiesel production from coconut fatty acid distillate. Iranian Journal of Chemistry and Chemical Engineering (IJCCE) 40(1): 343-355.

Yakar Y, Arslan H, Özçinar AB (2021) Siirt ekolojik şartlarında ikinci ürün olarak yetiştirilen bazı susam (Sesamum indicum L.) genotiplerinin yağ asidi kompozisyonlarının belirlenmesi. Gümüşhane Üniversitesi Fen Bilimleri Enstitüsü Dergisi 11(1): $27-$ 33.

Sevindik O, Selli S (2017) Üzüm çekirdek yağı eldesinde kullanılan ekstraksiyon yöntemleri, Gıda Dergisi 42(1): 95-103.

TGK (2012) Türk Gıda Kodeksi bitki adı ile anılan yağlar tebliği, Resmi Gazete, Sayı: 28262, 2012.

Şengün IY, Yücel E, Öztürk B, Kılıç G (2020) Haşhaş (Papaver somniforum) çeşitlerinin tohum yağlarinin yağ asidi kompozisyonu, toplam fenolik madde miktari, antioksidan ve antimikrobiyal aktiviteleri. Gida The Journal of Food 45(5).

Yücel Şengün I, Yücel E, Kılıç G, Öztürk B (2021) Kabak ve Kayısı çekirdeği yağlarının yağ asidi kompozisyonu, biyoaktif özelliklerinin belirlenmesi. Gıda 46: 608-20. 